http://jmscr.igmpublication.org/home/

ISSN (e)-2347-176x ISSN (p) 2455-0450

crossref DOI: https://dx.doi.org/10.18535/jmscr/v8i7.09

\title{
Incidence of Post Dural Puncture Headache (PDPH) Following Subarachnoid Block with 25G \& 27G Quincke Spinal Needles in Patients Posted for lower Abdominal Surgery
}

\author{
Authors \\ Dr Chandra Bhushan Kumar ${ }^{1}$, Dr. Ashutosh Kumar Jha ${ }^{2}$ \\ ${ }^{1}$ Junior Resident, Department of Anaesthesiology, KMC, Katihar, India \\ ${ }^{2}$ Professor \& Head, Department of Anaesthesiology, KMC, Katihar, India
}

\begin{abstract}
Introduction: Post dual puncture headache (PDPH) first described by Augustus Bier in $1898^{4}$ from his personal experience following a failed attempt of spinal anesthesia on himself due to mechanical difficulty. However his Assistant Hildebrandt ${ }^{4}$ successful in this regard in the same year and he also experienced PDPH. Two most important predictors of (PDPH) are type of spinal needle and its size $e^{5,6}$. In 1951 Hart and Whitacre ${ }^{7}$ reported lower PDPH rates with pencil point needle (Whitacre) than cutting (Quincke) type of needle. Till date, numerous studies demonstrated lower incidence of PDPH following spinal anaesthesia with the use of smaller size spinal needle in comparison to larger one.

Method: The study was a randomized, single blind, non placebo comparative study which includes 130 patients with ASA grade I \& II of either sex, between the ages 25 years to 50 years going for lower abdominal surgery. cases was divided randomly into two groups: Group A with $25 G$ and Group B with 27 $G$ Quincke needles. $3.5 \mathrm{ml} 0.5 \%$ Bupivaccine heavy was injected intrathecally at either $L_{2}-L_{3}$ or $L_{3}-L_{4}$ interspace in every patient after computer generated Randomization.

Result: In our study it is observed that the percentage of PDPH in group A $21 \%$ and that of group $B$ 4.6\%. Group A \& Group B were comparable with regard to age, sex distribution \& ASA grading so no statistical significant difference were found with regard to these parameters.

Conclusion: It can be concluded from our study, large bore cutting type of spinal needle (25G Quincke), producesmore PDPH than small bore cutting type of spinal needle (27G Quincke).
\end{abstract}

\section{Introduction}

Spinal anaesthesia (Subarachnoid anaesthesia SAB) first introduced by Augustus Karl Gustav Bier, a German surgeon who used $3 \mathrm{ml}$ of $0.5 \%$ cocaine intrathecally on six patients for lower extremity surgery in $1898^{1,2}$. Thereafter, fears of neurologic deficits and complications caused anaesthesiologists to use less of spinal anaesthesia. The development of novel intravenous anaesthetic agents and neuromuscular blockers coincided with the decreased use of spinal anaesthesia. In 1954, Dripps and Vandam described the safety of spinal anaesthetics in more than 10,000 patients and spinal anaesthesia wasagain revived $^{3}$. Spinal anaesthesia is most commonly used regional anaesthesia technique today.

Post dual puncture headache (PDPH) first described by Augustus Bier in $1898^{4}$ from his personal experience following a failed attempt of 


\section{JMSCR Vol ||08||Issue $\| 07||$ Page 40-45||July}

spinal anesthesia on himself due to mechanical difficulty. However his Assistant Hildebrandt ${ }^{4}$ successful in this regards in the same year and he also experienced PDPH.

Two most important predictors of (PDPH) are type of spinal needle and its size ${ }^{5,6}$. In 1951 Hart and Whitacre $^{7}$ reported lower PDPH rates with pencil point needle (Whitacre) than cutting (Quincke) type of needle. till date, numerous studies demonstrated lower incidence of PDPH following spinal anaesthesia with the use of smaller size spinal needle in comparison to larger one.

\section{Aims and Objectives}

This study was done to compare the incidence, onset, severity and duration of PDPH between Group A (25G Quincke needle) and Group B (27G Quincke needle).

\section{Method}

The study was a randomized, single blind, non placebo comparative study which includes 130 patients with ASA grade I \& II of either sex, between the ages 25 years to 50 years going for lower abdominal surgery. Cases was divided randomly into two groups: Group A with $25 \mathrm{G}$ and Group B with $27 \mathrm{G}$ Quincke needles. 3.5 ml 0.5\% Bupivaccine heavy was injected intrathecally at either L2-L3 or L3-L4 interspace in every patient after computer generated Randomization. At the end of the operation, a decrease of at least two segments regression of maximal sensory block was sought; if not present we checked the parameters every 10 mins interval by Pin prick method. After achieving aforesaid criteria along with cardiovascular stability patients were allowed to shift to the ward. In the post operative period the frequency and severity of PDPH were noted upto the 5thpost operative day. Other complications (if any) were also noted. Post operative analgesia was provided with inj. Diclofenac (water soluble) 75mg i.m. 12 hourly7 along with Inj. Tramadol $100 \mathrm{mg}$ i.m. 8 hourly for first 48 hours. After then oral NSAID was given along with oral $\mathrm{H} 2$ blocker. Occurrence of PDPH was treated by bed rest, enhancement of fluid intake, analgesics, caffeine and avoidance of straining. In refractory, PDPH, treatment protocol was epidural blood patch.

\section{Result and Analysis}

\section{1) Comparison of Demographic Data's of Both Groups}

Group A \& Group B were comparable with regard to age, sex distribution \& ASA grading so no statistical significant difference were found with regard to these parameters.

Table 1: Comparison of demographic data's

\begin{tabular}{c|c|c|c|}
\hline PARAMETERS & GROUP - A & GROUP - B & p- VALUE \\
\hline $\begin{array}{c}\text { AGE } \\
(25-32 \text { YRS })\end{array}$ & $\mathbf{1 9}$ & $\mathbf{1 5}$ & \\
$(33-40$ YRS & $\mathbf{1 5}$ & $\mathbf{2 4}$ & $\mathbf{0 . 7 5 1}$ \\
$(41-50$ YRS $)$ & $\mathbf{3 1}$ & $\mathbf{2 6}$ & \\
\hline $\begin{array}{c}\text { SEX RATIO } \\
\text { (MALE:FEMALE) }\end{array}$ & $\mathbf{3 5 : 3 0}$ & $\mathbf{3 0 : 3 5}$ & $\mathbf{0 . 6 0 2}$ \\
\hline $\begin{array}{c}\text { ASA GRADE } \\
\text { ( I : II })\end{array}$ & $\mathbf{5 0 : 1 5}$ & $\mathbf{5 3 : 1 2}$ & $\mathbf{0 . 5 2 0}$ \\
\hline
\end{tabular}

\section{2) Comparison of Incidence of PDPH in Both Groups}

Table 5: Incidence of PDPH in both groups

\begin{tabular}{|c|c|c|}
\hline $\begin{array}{c}\text { TOTAL NUMBER OF } \\
\text { PATIENTS }=130\end{array}$ & GROUP $-\mathrm{A}(\mathrm{n}=65)$ & GROUP B $(\mathrm{n}=65)$ \\
\hline PATIENTS HAVING PDPH & 14 & 3 \\
\hline PERCENTAGE & $21 \%$ & $4.6 \%$ \\
\hline
\end{tabular}




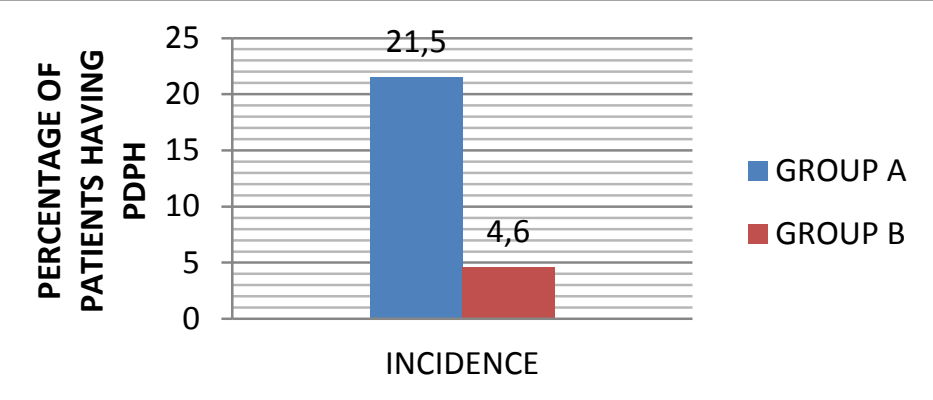

Graph 1: Comparison of incidence of PDPH

\section{3) Comparison of Severity of PDPH}

Table 6: Shows Severity of PDPH

\begin{tabular}{|l|c|c|c|c|}
\hline \multicolumn{1}{|c|}{$\mathrm{n}=130$} & \multicolumn{2}{|c|}{ GROUP $-\mathrm{A}(\mathrm{n}=65)$} & \multicolumn{2}{c|}{ GROUP $-\mathrm{B}(\mathrm{n}=65)$} \\
\hline SEVERITY $\downarrow$ & $\begin{array}{c}\text { NUMBER OF PATIENTS } \\
\text { ACCORDING TO SEVERITY } \\
(\mathrm{n}=14)\end{array}$ & $\begin{array}{c}\text { NUMBER OF PATIENTS } \\
\text { ACCORDING TO SEVERITY } \\
(\mathrm{n}=3)\end{array}$ & $\%$ \\
\hline MILD & 10 & 71.4 & 3 & 0 \\
\hline MODERATE & 3 & 21.4 & 0 & 0 \\
\hline SEVER & 1 & 7.14 & 0 & 0 \\
\hline
\end{tabular}

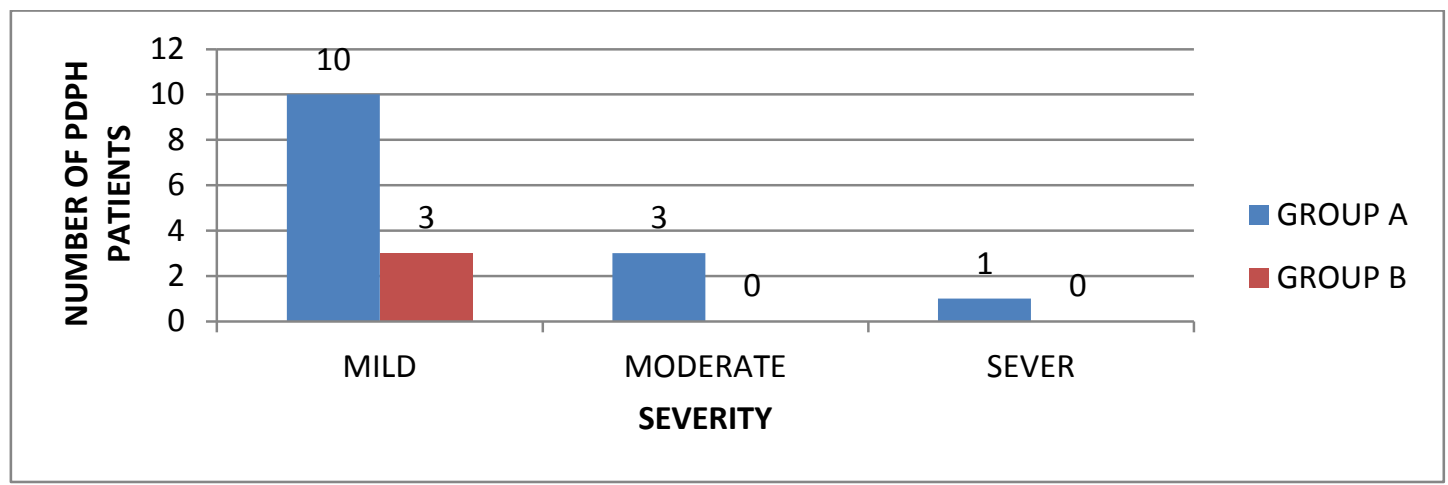

Graph 2: Comparison of severity of PDPH

\section{4) Comparison of Onset of PDPH}

Table 7: Onset of PDPH

\begin{tabular}{|c|c|c|c|c|}
\hline $\mathrm{n}=130$ & \multicolumn{2}{|c|}{ GROUP $-\mathrm{A}(\mathrm{n}=65)$} & \multicolumn{2}{c|}{ GROUP $-\mathrm{B}(\mathrm{n}=65)$} \\
\hline $\begin{array}{c}\text { ONSET IN } \\
\text { HOURS } \downarrow\end{array}$ & $\begin{array}{c}\text { NUMBER OF } \\
\text { PATIENTS }(\mathrm{n}=14)\end{array}$ & $\%$ & $\begin{array}{c}\text { NUMBER OF } \\
\text { PATIENTS }(\mathrm{n}=3)\end{array}$ & $\%$ \\
\hline 6 & ------ & -- & 33.33 \\
\hline 24 & 1 & --- & 1 & 66.66 \\
\hline 36 & 4 & 28.57 & 2 & \\
\hline 48 & 8 & 57.14 & -- & - \\
\hline 72 & 1 & 7.14 & - & \\
\hline
\end{tabular}

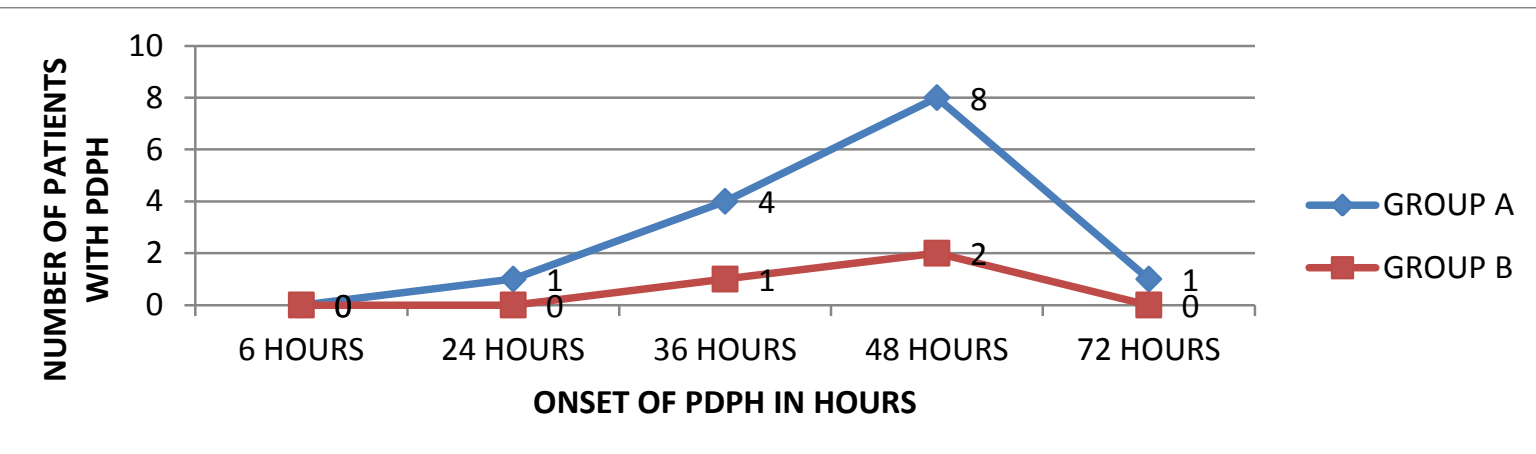

Graph 3: Comparison of onset of PDPH 


\section{5) Comparison of Duration of PDPH}

Table 8: Shows duration of PDPH

\begin{tabular}{|c|c|c|c|c|}
\hline $\mathrm{n}=130$ & \multicolumn{2}{|c|}{ GROUP $-\mathrm{A}(\mathrm{n}=65)$} & \multicolumn{2}{c|}{ GROUP $-\mathrm{B}(\mathrm{n}=65)$} \\
\hline $\begin{array}{c}\text { DURATION IN } \\
\text { HOURS }\end{array}$ & $\begin{array}{c}\text { NUMBER OF } \\
\text { PATIENTS }(\mathrm{n}=14)\end{array}$ & $\%$ & $\begin{array}{c}\text { NUMBER OF } \\
\text { PATIENTS }(\mathrm{n}=3)\end{array}$ & $\%$ \\
\hline$<24$ & 10 & 71.42 & 3 & 100 \\
\hline $24-48$ & 3 & 21.42 & --- & --- \\
\hline$>48$ & 1 & 7.14 & --- & --- \\
\hline
\end{tabular}

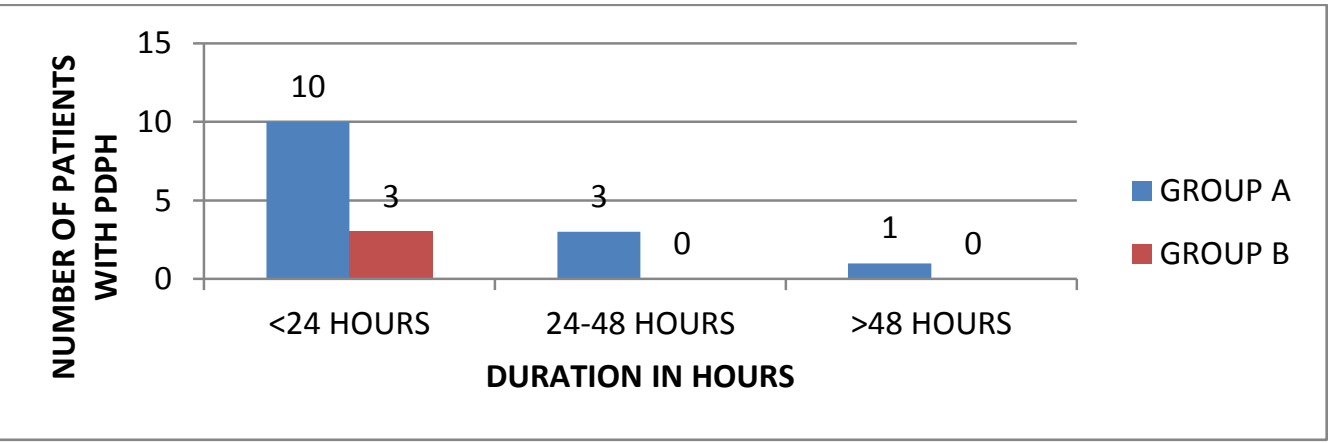

Graph 4: Comparison of duration of PDPH

\section{Discussion}

This prospective observational cohort study was done to compare the incidence of PDPH following spinal anaesthesia through $25 \mathrm{G}$ and $27 \mathrm{G}$ Quincke spinal needles for lower abdominal surgeries posted at Katihar Medical College \& Hospital.

A total of 130 patients between 25-50 years of age group belonging to ASA- I \&II were selected into two groups i.e., Group A (25G Quincke needle) and Group B (27G Quincke needle).

Spinal anaesthesia was administered in sitting position at $\mathrm{L}_{2}-\mathrm{L}_{3}$ or $\mathrm{L}_{3}-\mathrm{L}_{4}$ interspace through either $25 \mathrm{G}$ or $27 \mathrm{G}$ Quincke spinal needles. About $3.5 \mathrm{ml}$ Bupivacaine $^{8}$ heavy was injected intrathecally.

Incidence, onset, duration and severity of PDPH were noted as primary assessment following spinal anaesthesia up to 5 days.

The demographic data with respect to age, sex and ASA grade were comparable among the two groups with no statistical difference $(\mathrm{P}>0.05)$.

We choose adult of either sexes aged between 25 to 50 years undergoing lower abdominal surgeries only to exclude maximum biases due to selection of patients and surgeries and to confirm uniformity. The types of surgical cases performed were also similar, with similar times for anaesthesia and surgery in both the groups.
In our study there were no serious adverse effects in any of the patients between the two groups who received Bupivacaine heavy. This was similar to findings by all the studies done previously with this preparation.

Lower abdominal surgeries performed under spinal anaesthesia are less hazardous than general anaesthesia. Nowadays it is a common and acceptable anaesthetic practice throughout the world. Headache after dural puncture is a complication of spinal anaesthesia and is believed to result from leakage of CSF both at the time of dural puncture and probably more important due to continuous leak afterwards. ${ }^{9}$ Post dural puncture headache is a complication that should not be treated lightly. There is potential considerable morbidity due to post dural puncture headache and there are reports of PDPH symptoms lasting for months or years ${ }^{10}$. Untreated PDPH may lead to subdural haematoma $^{11}$ and even death may occur following bilateral subdural haematoma. ${ }^{12}$ Therefore anaesthesiologist are advised to prevent PDPH by optimizing the controllable factors like spinal needles size as well as shape while conducting spinal ansesthesia. Obstetric patients are at high risk of PDPH than nonobstetric females under 40 years of age ${ }^{13}$. Indeed, 
the highest incidence of PDPH is in the parturient and may partly explain higher incidence of PDPH in females as a whole. ${ }^{14}$

Diagnosis of postdural puncture headache depends upon the body position; the pain is aggravated by sitting or standing and relieved or decreased by lying down flat. ${ }^{15}$

Apart from other factors, post dural puncture headache is related to the size as well as the type of spinal needle used ${ }^{5,6}$. It is progressively reduced with the use of smaller size spinal needles ${ }^{16}$. Pencil point needles produce less damage to the dural fibres and allow the hole to close more readily. Thus they have a lower incidence of post dural puncture headache than cutting needle tip designs ${ }^{17}$.

The overall incidence of post dural puncture headache ranges from $0 \%$ to $37 \%$ as reported by various authors Reported frequency of PDPH ranges from $4 \%^{18}$ to $40 \%{ }^{19}$ with Quincke spinal needle used in young females. Ross et al reported PDPH in $9 \%$ of patients. In the study by Roheena and Colleagues, severity of PDPH was from mild to moderate. None of the patients complained of severe PDPH. It was more on $1^{\text {st }}$ post operative day and gradually decreased on the subsequent days.

Incidence of PDPH with 27 gauge Quincke needle ranges from $1.1 \%^{20}$ to $12.8 \%$. However, in a recent study by Muhammad et al frequency of PDPH was $0 \%$ with $27 \mathrm{G}$ Quincke spinal needle when spinal anaesthesia was administered for caesarean section.

In a study by Viitanen et al, PDPH incidence was $8.5 \%$. It was mild in $4 \%$, moderate in $3 \%$ and severe in $1 \%$ of patients. Symptoms started on first or second day after spinal injection and lasted for 3 days.

In our randomized study, the incidence of PDPH was $21.5 \%$ with $25 \mathrm{G}$ quincke needle and $4.6 \%$ with $27 \mathrm{G}$ Quincke needle. There was no severe PDPH in either of the group our study, therefore, clearly demonstrated a significant reduction in incidence of PDPH when smaller size Quincke needle was used as compare to larger ones. In a study by Landau et al, incidence of PDPH with $27 \mathrm{G}$ whit acre needle was less than $1 \%$. However a study by Shah and colleagues which closely resembles our study, demonstrated PDPH incidence was $20 \%$ with $25 \mathrm{G}$ Quincke needle and $12.5 \%$ with $27 \mathrm{G}$ Quincke needle

\section{Conclusion}

Post Dural Puncture Headache (PDPH) is a well known complication following spinal Anaesthesia since its first case report. The two principal determinant factors for development of PDPH are the type and the size of the spinal needles.

It can be concluded from our study, large bore cutting type of spinal needle(25G Quincke), produces more $\mathrm{PDPH}$ than small bore cutting type of spinal needle (27G Quincke).

Therefore we recommend routine use of smaller size Quincke needle (27G) while performing spinal anaesthesia in patients between 25- 50 years of age group posted for lower abdominal Surgeries.

\section{References}

1. Bier A. Experiments regarding the cocainization of the spinal cord. Dtsch $\mathrm{Z}$ Chir. 1899; 51: p. 361-369.

2. Marx G. The first spinal anesthesia. Who deserves the laurels? RegAnesth.1994; 19: p. 429-430.

3. Dripps R, Vandam L. Long-term followup of patients who received 10,098spinal anesthetics: failure to discover major neurologic sequelae. JAMA. 1954;156: p. 1486-1491.

4. Gerancher JC, Liu SS: complications of Neuraxial (spinal/epidural/caudal) Anaesthesia In : Jonathan LB, Lawrence JS ed. Anaesthesia and Perioperative complications. 2nd edition .Mosby ;1999,p.50-65

5. Reid JA,Thorburn J. editorial II Headache after spinal anaesthesia. Br J Anaesth 1991;67:674-7. 
6. Kang SB, Goodnough DE, Lee YK, et al. A Comparison of $26 \mathrm{G}$ and $27 \mathrm{G}$ needles for spinal anaesthesia for ambulatory surgery patients. Anaesthesiology 1992;76(5):7348

7. Goodman Gilman Pharmocology: $12^{\text {th }}$ edition; page no. 697 Miller's Anesthesia: $7^{\text {th }}$ edition; page no. 814 .

8. Miller Anesthesia: $7^{\text {th }}$ edition; page no. 929

9. Wayne Kleinman, Maged Mikhial spinal <epidural and caudal blocks. In: GE Morgan, MSMIkhial, MJ Murray. Clinical Anesthesiology $4^{\text {th }}$ edition 2006, page no. 319.

10. Gerrtse BM, Gielen MJ. Seven months delay for epidural blood patch in PDPH. Eur J Anesthesiol 1999;16:650-1.

11. Zeidon A, Farhat O, Maaliki H, Baraka A. Does PDPH left untreated lead to subdural haematoma? Case report and review of literature. Int J Obstet Anesth 2006;15 (1):50-8.

12. Grieff J, Cousins MJ. Subdural- arachnoid and extradural anaesthesia. In Nimmo WS, Row Botham DJ, Smith G. Anasethesia $2^{\text {nd }}$ edition Blackwell Scientific publication London 1994:p1411-54.

13. Ahan S, Kitchen N, Jenkins C, Margary J. Incidence of PDPH following spinal anaesthesia for lower segment caesarean section with $25 \mathrm{G}$ polymedic spinal needle. J Pak Med Assoc 1996;46:278-81.

14. Hopkinson JM, Samaan AK, Russell IF, Birks RJS, Patrick MR. A comparative multicentre trial of spinal needles caesarean section anaesthesia 1997;52: 998-1014.

15. Garry M, Davies S. Failure of regional blockade for caesarean section. Int $\mathrm{J}$ Obstet Anesth 2002;11:9-12.

16. Lambert DH, Herley RJ, Hertwig L, Datta S. Role of needle gauge and tip configuration in the production of lumbar puncture headache. Reg Anesth 1997; 22:66-72.

17. McConachie I, Mc Geachie J. Regional anaesthetic techniques in: Thomas EJH, Peter JC. Wylie and Churchill- Davidson's A practice of Anesthesia, $67^{\text {th }}$ edition 1995; page 718.

18. Nazli H, Subhana T, Tayyab M. spinal anaesthesia for caesarean section. JSP 2002,7(1):19-21.

19. Roheena W, Nasreen L, Fayyaz AQ, Akbar SJ. The frequency of PDPH in different age groups. J Coll Physicians Surg Pak 2006;16(6):389-92.

20. Lynch J, Kasper SM, Strick K, Topalidis K, Schaff H, Zeeh D, Krings- Ernst I. The use of Quincke and Whitacre $27 \mathrm{G}$ in orthopedic patients: incidence of spinal anaesthesia and PDPH. Anesth Analg 1994:79:124-8. 